\title{
QUASI-CONVOLUTION OF ANALYTIC FUNCTIONS WITH APPLICATIONS
}

\author{
K. O. BABALOLA
}

Abstract. In this paper we define a new concept of quasi-convolution for analytic functions normalized by $f(0)=0$ and $f^{\prime}(0)=1$ in the unit disk $E=\{z \in \mathbb{C}:|z|<1\}$. We apply this new approach to study the closure properties of a certain class of analytic and univalent functions under some families of (known and new) integral operators.

Mathematics subject classification (2000): 30C45.

Key words and phrases: Quasi-convolution, analytic and univalent functions.

\section{REFERENCES}

[1] S. AbDulhalim, On a class of analytic functions involving the Salagean differential operator, Tamkang J. Math., 23 (1) (1992), 51-58.

[2] F. M. AL-OBOUDI, On univalent functions defined by a generalized Salagean operator, Int. J. Math. \& Math. Sc. 27 (2004), 1429-1436.

[3] K. O. BABAlOLA, Some remarks on certain Bazilevic functions, J. Nig. Asso. Math. Physics, 10 (November 2006), 171-176.

[4] K. O. BABAlOLA and T. O. OpOOLA, Iterated integral transforms of Caratheodory functions and their applications to analytic and univalent functions, Tamkang J. Math., 37 (4) (Winter 2006), 355-366.

[5] K. O. Babalola and T. O. Opoola, On the coefficients of certain analytic and univalent functions, Advances in Inequalities for Series, (Edited by S. S. Dragomir and A. Sofo), Nova Science Publishers (http://www . novapublishers. com) (2008), 5-17.

[6] S. D. Bernard, Convex and starlike functions, Trans. Amer. Math. Soc. 135 (1969), 429-446.

[7] P. L. DuREN, Univalent functions, Springer Verlag. New York Inc. 1983.

[8] I. B. Jung, Y. C. KIM and H. M. SRIVASTAVA, The Hardy space of analytic functions associated with certain one-parameter families of integral operators, J. Math. Anal. Appl. 176, (1993), 138-147.

[9] J. S. KANG, S. OWA and H. M. SRIVASTAVA, Quasi-convolution properties on certain subclasses of analytic function, Bull. Belg. Math. Soc. 3, (1996), 603-608.

[10] T. H. MacGregor, Functions whose derivatives have positive real part, Trans. Amer. Math. Soc. 104 (1962), 532-537.

[11] S. S. Miller and P. T. Mocanu, Second order differential inequalities in the complex plane, J. Math. Anal. Appl. 65, (1978), 289-305.

[12] S. S. MiLler and P. T. MocANU, Differential Subordination, Theory and Applications, Marcel Dekker, 2000.

[13] K. I. NOOR and M. A. NoOR, On certain classes of analytic functions defined by Noor integral operator, J. Math. Anal. Appl. 281, (2003), 244-252.

[14] S. OwA, The quasi-Hadamard product of certain analytic functions, Current Topics in Analytic Functions Theory (Edited by H. M. Srivastava and S. Owa) World Scientific Publishing Co. Singapore, New Jersey, London and Hongkong, (1992), 234-251.

[15] T. O. OpOOLA, On a new subclass of univalent functions, Mathematica (Cluj) 36, 59 (2)(1994), $195-200$.

[16] G. S. SAlagEAN, Subclasses of univalent functions, Lecture Notes in Math. 1013 (1983), 362-372. Springer-Verlag, Berlin, Heidelberg and New York.

[17] O. SHIGEYOSHI, Properties of certain integral operators, Georgian Math. J. 2 (5) (1995), 535-545. 
[18] R. SingH, On Bazilevic functions, Proc. Amer. Math. Soc. 38 (1973), 261-271.

[19] K. YamaGUCHI, On functions satisfying $\operatorname{Re}\{f(z) / z\}>0$, Proc. Amer. Math. Soc. 17 (1966), 588-591. 